\title{
The challenge of monitoring and evaluation under the new aid modalities: experiences from $R$ wanda*
}

\author{
Nathalie Holvoet \\ Institute of Development Policy and Management, University of Antwerp, \\ Lange St. Annastraat 7, 2000 Antwerpen, Belgium \\ Email: nathalie.holvoet@ua.ac.be \\ and \\ HeIDy Rombouts \\ Belgian Technical Cooperation, Hoogstraat I47, Iooo Brussel, Belgium
}

\section{A B S T R A C T}

Monitoring and evaluation $(\mathrm{M} \& \mathrm{E})$ are sensitive issues in relations between donor agencies and recipient governments, especially in a time when the responsibility for implementing aid activities is shifting towards recipients. This paper deplores that, so far, donors and recipients have adopted an overly technocratic approach to $\mathrm{M} \& \mathrm{E}$, largely disregarding broader institutional and systemic issues. Using case study material from Rwanda, we illustrate that assessments regarding the quality of a country's M\&E efforts may differ sharply depending upon one's perspective. At the core of the matter is 'the denial of politics', one of the most serious flaws in the new aid paradigm promoted in the OECD's 2005 'Paris Declaration'. We argue that while a narrowly defined technocratic vision of M\&E may seem 'politically neutral', in fact it may jeopardise M\&E's functions of 'accountability' and 'feedback'. This can eventually undermine the effective implementation of some of the key principles of the 'new aid approach'.

* The authors thank the interviewees, anonymous referees and Robrecht Renard for useful comments and suggestions. The views expressed in this paper are those of the authors, and should not be attributed to either the Institute of Development Policy and Management, University of Antwerp, or the Belgian Technical Cooperation. 
Since the turn of the century, a major shift has taken place in aid modalities advocated for low-income countries. Instigated by analyses of previous aid (in)effectiveness, key principles that are now wholeheartedly embraced include country-ownership, long-term and holistic vision, country-led partnership and results-orientation. The new aid paradigm imposes a huge reform agenda upon donors and recipients, and is most clearly set out in the 2005 Paris Declaration (OECD/DAC 2005). In short, recipients are expected to elaborate sound comprehensive policies that aim at poverty reduction, and that involve broad-based participation from state and non-state actors (Poverty Reduction Strategy Papers [PRSPs] and sector programmes). Furthermore, they need to strengthen and build resultsoriented frameworks and arrangements for planning, implementation, monitoring and evaluation. Donors are expected to share information amongst one another, harmonise their aid management procedures and align their assistance programmes, as much as possible, to the policy and institutional frameworks of the partner countries. In practice, it is an evolution from major donor control over the substance and procedures of clearly delineated projects and/or programmes towards donor influence over broader national and sectoral policies and procedures. Aid modalities that most obviously match this evolution are sectoral and general budgetary support, whereby donors directly disburse aid monies towards sectoral and/or national budgets, combined with policy dialogue, technical assistance and well-aligned pilot projects aimed at improving policies and procedures that should eventually lead to poverty reduction on the ground.

Monitoring reform progress under the auspices of the OECD/DAC uses a set of twelve indicators, and covers thirty-four partner countries with data from sixty donors. ${ }^{1}$ Results of the 2006 survey indicate, so far, that progress has not been uniform, with major differences between donors, recipients and the specific dimensions of the aid reform agenda (OECD/DAC 2007a). Our case study focuses on Rwanda, a harmonisation pilot country for the Strategic Partnership with Africa (SPA) and the IMF (Development Gateway 2008). Rwanda was also among the seven countries included in the Joint Evaluation of General Budget Support I994-2004 (JEGBS), the most ambitious multi-country effort to evaluate budgetary support yet undertaken. The second section gives a brief overview of the evidence gathered so far. It leads to the conclusion that Rwanda is doing moderately well on several dimensions of the aid reform agenda, and so is one of the more successful cases.

This article focuses on 'monitoring and evaluation' (M\&E), one of the crucial dimensions of the aid reform agenda. The OECD/DAC (2002: 20) 
defines 'evaluation' as 'the systematic and objective assessment of an ongoing or completed project, programme or policy, its design, implementation and results', and 'monitoring' as 'a continuous management function that uses systematic collection of data on specified indicators to provide management and the main stakeholders of an ongoing development intervention with indications of the extent of progress and achievements of objectives and progress in the use of allocated funds' (ibid.: 28). Monitoring is thus rather descriptive and assesses whether different levels of an intervention (inputs, activities, outputs, outcomes and impact) are realised as expected, whereas evaluation necessitates more analytical depth to tackle the 'why' questions. While 'monitoring' and 'evaluation' are clearly distinct activities, they are highly complementary. Quoting Kusek and Rist (2004: 13), 'evaluation is a complement to monitoring in that when a monitoring system sends signals that the efforts are going off track then good evaluative information can help clarify the realities and trends noted with the monitoring system'. The basic functions of $\mathrm{M} \& \mathrm{E}$ are the fulfilment of 'accountability' towards funders, taxpayers and citizens on one hand, and, on the other, 'lesson learning' and 'feedback' towards management and policy makers (with the final aim to improve further interventions). The importance of $\mathrm{M} \& \mathrm{E}$ in the context of the new aid modalities may be understood from various angles. First, the establishment of well-functioning recipient $\mathrm{M} \& \mathrm{E}$ frameworks is crucial for the realisation of results-oriented, iterative and evidence-based policy making. Secondly, 'accountability' and particularly 'downward accountability', and not only learning, are central to the success of the new aid paradigm. The basic idea here is that non-state actors especially play key roles in both the supply and demand of information and accountability. As users themselves with 'grassroots' contacts with beneficiaries, they may be able to produce information about the implementation and impact of service delivery and policy processes. As actors in civil society representing various citizens' interests, they may wish to hold government accountable, requesting reliable information and objective assessments of outcomes. The establishment of well-functioning recipient $\mathrm{M} \& \mathrm{E}$ frameworks is also crucial for donors, particularly as they wind down their own parallel M\&E systems and become (largely) dependent upon the recipient's.

In spite of its importance, $M \& E$ has so far been neglected in the context of the new aid modalities, or at least a narrow technocratic vision of $\mathrm{M} \& \mathrm{E}$ has been adopted, by both recipient countries and donors. Several multicountry reviews (Holvoet \& Renard 2007; Lucas et al. 2004; World Bank 2002: 20, 2005) point to a bias towards methodological and technical issues, to the detriment of broader policy, institutional and systemic issues. 
This paper observes a similar phenomenon for Rwanda. Sections Three and Four broaden the information base from donor-instigated publications to other secondary information, complemented further with insights from primary data collected in Rwanda in 2006. Earlier and more extensive fieldwork by one of the co-authors (Rombouts 2004) helped us to contextualise our later findings.

In Section Five, we contend that these contrasting findings may most easily be understood when set against one of the most serious flaws in the new aid paradigm. The denial of the 'political dimension' in the Paris reform agenda is increasingly seen as a serious deficiency (Armon 2007), particularly when it comes to 'monitoring and evaluation'. Though the influence of politics in project and programme M\&E has long been acknowledged, it surprisingly seems to go unnoticed at the sectoral and national levels where the interests and stakeholders are multiplied. As the logic of the new aid paradigm is to put the national government in the driver's seat, one would expect national power relations and interests to become more prominent in $\mathrm{M} \& \mathrm{E}$. While ignoring the links between 'politics' and M\&E in the short-term may be convenient, eventually it may contaminate M\&E's central functions of 'accountability' and 'feedback', and so jeopardise the key principles of the new aid paradigm.

\section{NEW AID MODALITIES IN RWANDA: SOME BASICS}

In the wake of the 1994 genocide, the international donor community flocked to support Rwanda. Many donors later made the transition from humanitarian to structural aid, and at present, the country is highly aiddependent: between 1998 and 2004, aid averaged $20 \%$ of the Gross National Income (World Bank 2006). In the immediate recovery period, it was substantially higher (with an average of 6r \% over the period I994-6). 'Genocide guilt' 2 seems to have fuelled, in part, the financial generosity of international donors, and 'it opened the door to aid with a political dimension' (Purcell et al. 2006: I7). At the end of 2000, the World Bank/IMF endorsed Rwanda's interim PRSP, and its final PRSP was published in June 2002. Since its adoption, it has provided the general framework for donor assistance in Rwanda. Between 200I and 2004, I8-30\% of Rwanda's aid was delivered through budgetary support. The main budgetary donors included the United Kingdom, the World Bank, the EU and Sweden. Belgium, France, Germany, the Netherlands, USAID, Japan and Canada were among the main non-budgetary donors (Purcell et al. 2006). By mid 2006, Rwanda began preparing for the second round PRSP (this time called the 'EDPRSP', with ED standing for Economic 
Development). The Rwanda Development Partners Website (DPCG 2007) described the drafting process and anticipated a new version by May 2007. By December 2007, however, the document had not been released.

Rwanda is a harmonisation pilot for both the Strategic Partnership for Africa (SPA) and IMF initiatives (Development Gateway 2008). Donors have been regrouped as 'Development Partners', and together with the Government of Rwanda (GoR) they have set up an Aid Coordination, Harmonisation and Alignment framework. It is the highest-level coordination structure in Rwanda, drawing its membership from government representatives and heads of cooperation in bi- and multilateral agencies (MINECOFIN 2006). The Development Partners website includes resources and information, and may help to coordinate and improve development activities. Aid harmonisation in Rwanda is, however, hampered by the divide between budgetary and non-budgetary donors, with each camp strongly defending diverging opinions, particularly regarding political and governance conditions in the country (Purcell et al. 2006; Uvin 200I). On top and in line with this division, is the cleavage between francophone and anglophone-oriented donors (Browne 2007; Kanyarukiga et al. 2006; Purcell et al. 2006; Uvin 200I). Whereas Rwandan progress on harmonisation is rated 'low-moderate' in the 2006 Survey on Monitoring the Paris Declaration, the same survey considers 'ownership' (i.e. 'a country's ability to exercise effective leadership over its development policies and strategies') particularly outstanding (OECD/ DAC 2007b: 27-2). ${ }^{3}$

M\&E IN RWANDA FROM A NARROW TEGHNOCRATIG PERSPECTIVE

While many of the details described below are peculiar to the Rwandan situation, they are supportive of a bias towards methodological and technical issues, as noted in several reviews of recipient M\&E systems and arrangements (Holvoet \& Renard 2007; Lucas et al. 2004; World Bank 2002: 20, 2005). In practice, such reviews involve a strong focus on the handling of inputs, coupled recently with a focus on monitoring poverty outcomes and Millennium Development Goals (MDGs), an upsurge of new rounds of data collection, an emphasis on monitoring (to the detriment of evaluation), and an extolment of targets and indicators, sometimes referred to as 'indicatorism'. This fragmentary approach on the ground seems to match donors' visions of M\&E. Over the years, most recipient countries have been bombarded with Public Finance Management (PFM) assessment missions (see SPA-BSWG 2005: I5-I8). M\&E capacity has often been reduced to improve statistical data capacity, ${ }^{4}$ and targets and indicators are 
crucial for donors in the context of Performance Assessment Frameworks (PAFs). As the World Bank's Evaluation Capacity Development Unit states in its 2002 Annual Report, 'PRSPs and Bank/Fund Joint Staff Assessments often use the term $\mathrm{M} \& \mathrm{E}$ as a shorthand for financial tracking and national development indicators' (World Bank 2002: 20).

Within this narrow version of M\&E, Rwanda is not doing badly. On the contrary, as the Joint Evaluation of General Budget Support puts it (Purcell et al. 2006: 204), 'in recent years excellent progress has been made in constructing a modern public financial management (PFM) system in Rwanda'. Since 1997, two ambitious rounds of PFM reform have been held to rebuild a system that had totally collapsed during the I994 genocide. Whereas there remain considerable challenges, the GoR, with support of various donors, introduced a Medium-Term Expenditure Framework (MTEF) in 2000, which sets forth the basis for further PFM reforms (Purcell et al. 2006: 205). Furthermore, Rwanda is widely praised for fighting corruption (Amis et al. 2005: 6; Purcell et al. 2006). It scored $55^{\circ} 8$ (on a scale of o-IOo) on the sub-indicator 'control of corruption' in the latest 2007 update of the Kaufmann, Kraay and Mastruzzi governance indicators, whereas the regional average for SSA stands at $30^{\circ} 3$ (Kaufmann et al. 2007). On a critical note, however, the evaluation report states, 'while corruption is generally perceived as not being a problem in Rwanda, risks of subtle forms of corruption, such as exclusion patterns and concentration of economic power, might be increasing' (Purcell et al. 2006: S9).

The GoR has shown a keen interest in improving data collection, which is evident from the emphasis given to the Rwandan National Institute of Statistics (OECD/DAC 2007b). This has resulted, so far, in an upsurge of data collection, especially on poverty, and to a renewed interest in household surveys (e.g. the 2001 and 2005/o6 Enquêtes Intégrales sur les Conditions de Vie des Ménages, the 2001 and 2005 Demographic and Health Surveys, and the 200 I Core Welfare Indicators Questionnaire). With a score of $7 \mathrm{I}$ (scale of $0-100$ ) on the 2007 Statistical Capacity Building Indicator, ${ }^{5}$ Rwanda does better than most low- and middle-income countries in the world (average score of 66) as far as statistical capacity is concerned (World Bank 2008). The growing attention to qualitative, difficult-to-measure, issues has also given an impetus to survey approaches which seek to combine qualitative and quantitative methodologies, as well as to the usage of more participatory techniques. In the context of the first full PRSP, Rwanda conducted a Participatory Poverty Assessment (PPA) and introduced a mechanism (Ubudehe) for 'grassroots collective decision making and action' (Evans et al. 2006: 62). Additionally, the University of 
Butare, in collaboration with the Rwandan chapter of OSSREA (Organisation for Social Science Research in Eastern and Southern Africa), conducted M\&E exercises aimed at incorporating the visions of the population. In 2002, it published the results of the Poverty Reduction Policies Relevance Test, ${ }^{6}$ and in February 2006, a report based on Citizen Report Cards - a grassroots participatory method of data collection that provides insights into citizens' appreciation of services provided. Various sources highlighted the 'unprecedented levels of citizen participation' in these initiatives (Evans et al. 2006: 62). There are, however, others (Renard \& Molenaers 2003) who indicated that these processes were largely government-controlled and ignored the involvement of traditional independent M\&E demand side actors (e.g. civil society organisations or C.SOs).

There is more agreement among various sources on the fact that the significant upsurge in data collection stands in sharp contrast to a serious deficit in analysis of the data gathered (Amis et al. 2005: Io; Kanyarukiga et al. 2006; Mutebi et al. 2001: 35; Purcell et al. 2006). Data collected in the context of the Poverty Reduction Policies Relevance Test and the Citizen Report Cards are not explicitly linked to specific policies, and disaggregation to relevant social categories is mostly absent. Differential effects of measures on income groups, regions, and along urban-rural and gender lines remain underexplored. Evidently this severely hampers the usefulness of data collection for policy making and evaluation. A noteworthy attempt at moving beyond pure data collection and 'stocktaking' is the 2007 Preliminary Poverty Update Report, which is based on a comparison of results of the latest 2005/o6 household survey with the 2000/or exercise. It provides, for the first time, a frank overview of changes in poverty and inequality, documenting that unequal distributions of growth, in combination with high initial levels of inequality, have impaired the potential poverty-reducing effect of growth (NISR 2006). ${ }^{7}$ In various places, different layers of disaggregation are included (i.e. gender, urban/ rural, provinces). While this 'evaluative' initiative is laudable (identifying not only 'levels of outcomes' but also 'changes in outcomes'), there are still major shortcomings when it comes to the analytical and evaluative quality of the exercise. The analysis does not consider confounding factors to arrive at some measure of 'impact', it hardly explores the underlying reasons for varied performance, and it does not distinguish between implementation failures and conceptual flaws in policies.

The gap between data collection and analysis is certainly not unique to Rwanda (CGD 2006), nor is the emphasis on 'monitoring' at the expense of 'evaluation' (Holvoet \& Renard 2007; World Bank 2002: 20). In spite of the fact that the MINECOFIN 2005 Cabinet Paper on M\&E lends more 
importance to the evaluative function, the earlier emphasis on monitoring in Rwanda's 2002 PRSP persists. As in other countries, the impression is often given that monitoring somehow also constitutes evaluation. We acknowledge that monitoring is of the utmost importance, and even that more energy needs to be devoted to it than to evaluation, but there remains a persistent need for the latter. One of the consequences of favouring monitoring over evaluation is that the focus is much more on performance stocktaking ('Were the targets met?'), rather than on performance analysis ('Why were the targets not met?'), or on questioning the usefulness of the targets themselves (and/or of the interventions designed to meet them).

In line with the above-mentioned efforts in data collection and monitoring, Rwanda is also improving its indicators and targets. From the Interim PRSP to the full PRSP and the Annual Progress Report, the list of indicators has become more refined. In the context of PRSPs, Performance Assessment Frameworks (PAFs) and new aid modalities in general, there is an evolution towards a greater focus on a limited set of 'aggregate' indicators and targets. We do not argue against concise lists of indicators, but a unique focus on 'aggregates' easily hides distortions at disaggregated levels (Ravallion 2006, 2007). This evolution is particularly relevant in the context of countries such as Rwanda, where concerns are raised over increasing levels of inequality and potentially exclusionary poverty reduction policies and outcomes (Evans et al. 2006). According to Prennushi et al. (2001: II I), 'the decision on the level of disaggregation of indicators is as important as the choice of indicators itself'. Particularly relevant in the Rwandan case are existing, but often concealed, horizontal inequalities ${ }^{8}$ and how the government is handling them. While these tend to go unnoticed in the PRSP's focus on the 'aggregate picture', Brown and Stewart (2007) identify at least three instrumental reasons for their importance: horizontal inequalities can negatively impact poverty reduction targets and economic efficiency; they can be a source of violent conflict. The move towards the 'aggregate level' clearly suits the GoR (e.g. it is virtually taboo to refer to ethnic differences) ${ }^{9}$ as does the narrow technocratic vision on $\mathrm{M} \& \mathrm{E}$ in the Paris Declaration. In what follows, we broaden the scope of the discussion from the methodological and technical to the institutional and systemic.

... AND FROM AN INSTITUTIONALAND SYSTEMICPERSPECTIVE

While institutional and systemic issues have generally been neglected in $\mathrm{M} \& \mathrm{E}$, under the new aid modalities a gradual recognition of their 
importance has started to emerge, at least within some donor agencies (Bedi et al. 2006; GTZ/BMZ 2004; Kusek \& Rist 2004). So far, however, this has not been translated into changes in donor assessment exercises or practices on the ground (in Rwanda or elsewhere). In what follows, we will try to fill this gap by focusing on: (i) the institutional set-up of Rwanda's $\mathrm{M} \& \mathrm{E}$ system, including issues of oversight, independence, horizontal and vertical integration; (ii) the role of non-state actors (parliament, the Auditor General's Office, research institutes, national and international NGOs, etc.) as sources of M\&E supply and demand; and (iii) donors' M\&E behaviour in Rwanda.

\section{Institutional set-up}

The 2002 PRSP installed an institutional M\&E framework, and a separate Poverty Observatory to act as an overall coordinator of the system. However, the latter was quickly abolished with M\&E oversight taken over by the Development and Planning Unit. In 2005, new changes were announced in a cabinet paper (MINECOFIN 2005) that aimed to correct weak $\mathrm{M} \& \mathrm{E}$ institutionalisation. A logical structure for an $\mathrm{M} \& \mathrm{E}$ framework linking different levels (line ministries, decentralised units, etc.) to different tasks (setting targets, collecting data, etc.) was set out. Five years on, little tangible progress has been made in terms of its institutional set-up or integration. Again and again a new structure, format, chain or flow is proposed, all largely unsuccessful. By mid 2006, the latest changes proposed in the 2005 Cabinet Paper have not yet materialised. Due to a never-ending cycle of reforms, changes are never practically thought through, implemented, tried out and left to mature. Elsewhere, such changes in the institutional framework have been noted as well. Bamberger (I99I) reported on experiences from South Asia where, due to inter-agency competition to control $\mathrm{M} \& \mathrm{E}$ and fears of units becoming too powerful and threatening, institutional arrangements never lasted for longer than three years. Establishing coherent and well-functioning M\&E institutions has indeed proven difficult (GTZ/BMZ 2004; World Bank 2003, 2005), even in countries where substantial improvements in sub-components such as statistical data capacities are made (World Bank 2005). An M\&E system groups many actors with different responsibilities: line ministries, decentralised entities, statistical offices, etc. During different M\&E stages - data collection, analysis, and feedback - the need for coordination is high, but also problematic. In Rwanda, the latest proposed reforms make sense, yet more seems needed to deal effectively with M\&E's institutional weaknesses. Three elements deserve particular attention. 
First, problematic vertical and horizontal integration; second, the lack of institutional independence; and third, unclear mandates and relationships.

Obviously, moving towards results-based management and budgeting can only work when there is a minimal degree of horizontal and vertical integration. This involves line ministries and decentralised levels that supply central ministries with the necessary information on intermediate and final outcomes, and central ministries that provide line ministries and decentralised levels with realistic projections on future budgets, as well as support in the development of sectoral and decentralised M\&E systems. Currently, line ministries operate relatively independently and most do not have M\&E systems (including Management Information Systems or MIS) in place. Where such systems are operational (mainly in education and to a lesser extent in health ministries), there are no clear-cut plans about how to integrate them into an overarching $\mathrm{M} \& \mathrm{E}$ framework. Central entities, such as the Rwandan MINECOFIN, do not seem powerful enough to take proactive measures to set up sound $\mathrm{M} \& \mathrm{E}$ (including MIS) activities at the line ministry level, as well as ensuring a minimal degree of integration (Amis et al. 2005). The lack of horizontal integration is problematic: it hampers central oversight and control over the quality of data and analysis, it limits cross-readings between sector and country-level survey data, and so negatively affects analytical quality (Kanyarukiga et al. 2006: 2I), ${ }^{10}$ and it jeopardises the use of data for policy making. Improved integration will need more discipline on the side of line ministries (using uniform formats, establishing M\&E departments, etc.), a more engaged role/mandate at the central level as well as capacity building at the line ministry level.

Decentralised entities play an important role in the new M\&E framework and this will necessitate adequate vertical integration. Statistical flows of information between various levels of government require rigorous set-ups and treatment of data, implying discipline on the supply side. Such discipline is unlikely to occur without strong political support. In Rwanda, such political support can be mustered through a strong party structure present down to the lowest administrative level in the country. But given the authoritarian culture of the country this may lead to 'desirable' rather than accurate data being 'produced'. Another problematic aspect is that local entities are viewed as mere outposts for data collection (MINECOFIN 2005). The new M\&E framework, as presented in the 2005 Cabinet Paper, views local entities mainly as information collectors feeding into the national level. In the context of the latest decentralisation reform there is obviously also need for a reverse information stream, and 
for analysis and feedback into local decision making. Decentralisation and $\mathrm{M} \& \mathrm{E}$ by local authorities are processes that should be compatible with each other in terms of mandate and capacities; otherwise they risk being mutually undermining. At first sight the administrative staff reform accompanying the 2006 decentralisation substantially increased the capacities of the decentralised levels. It led to a severe reduction of staff at the ministries (central level) in order to employ them at lower levels. On the ground, however, it seems that the 2006 reforms tended to destroy earlier local capacity building initiatives that were part of the 200I decentralisation. Staff transferred from the central level often did not arrive and/or they were sent to districts they did not know. ${ }^{11}$ This, in combination with the replacement of existing district staff by bettertrained but often inexperienced personnel, tended to erase institutional memory, which obviously hinders local data collection and analysis (Elkins 2006: 9).

In addition to staff reform, the current decentralisation process has substantially increased the amount of money transferred to the districts, making the decentralisation more 'real' than before. To ensure operational accountability of the local entities, each district was asked to develop and sign a 'performance contract' (contrat de performance) with the President of the Republic. While an agreement that includes clear-cut indicators and targets may be an effective way of 'management for results', a closer look at these contracts and the way in which they have been elaborated shows that they risk degrading into 'management by results'. The contracts were designed rather quickly after the local elections of early 2006, at times when baseline data for the new districts was generally absent. Not surprisingly, contracts often incorporate non-realistic goals, such as moving from I \% of improved toilets to $100 \%$ in one year. The question now is how these contracts will be used in the future. If they become instruments to judge district performance, they risk leading to biased $\mathrm{M} \& \mathrm{E}$ at district level, where undoubtedly they will be 'cleaned up'. When contract performance is evaluated at central level, its unrealistic character provides central authorities with the perfect excuse to dismiss whoever they want. In a strong, hierarchical top-down party system such as Rwanda's, arbitrariness is not to be excluded and performance contracts risk serving as sham arguments rather than tools of objectivity and accountability.

Horizontal and vertical integration are also seriously hampered by the lack of clear M\&E mandates and relationships. Defining a wellfunctioning M\&E system is not a stroke-of-the-pen exercise. Defining and dividing responsibilities in a clear manner as well as establishing good 
working relationships and information flows is essential. Some examples may make this matter clear. While the Strategic Planning Unit considers itself the main M\&E unit within MINECOFIN, not all members agree upon its tasks. The division of labour among the Strategic Planning Unit and the National Institute of Statistics is not clear-cut. Data collection, which is currently given great importance, obviously falls under the responsibility of the statistical agency. But by mid 2006, it was not entirely clear which of the two units should consolidate and analyse information from country-wide M\&E exercises, such as the Household Living Conditions Survey, Demographic and Health Surveys, Sector Reviews and the Annual Progress Reports.

A final important issue regards independence and impartiality, both crucial elements in all $\mathrm{M} \& \mathrm{E}$ guidelines and standards. ${ }^{12}$ Independence can be bolstered by the location of the units responsible for M\&E: a unit close to the operational level may strengthen feedback but also weaken $\mathrm{M} \& \mathrm{E}$ independence. Line ministries are tasked, for example, with the identification of key performance indicators. No other actors, including more impartial ones, are part of this identification process. The Strategic Planning Unit of MINECOFIN acts as a coordinator. However, it is not strongly enough linked to the M\&E framework, nor given a sufficiently strong mandate to improve its impartiality. Nor does the M\&E institutional framework incorporate independent actors (e.g. representatives of parliament and/or civil society) as described further below. Similarly, no mention is made of independent research institutes or the Rwandan Evaluation Network. Donor representatives can have an independent say when participating in joint (sector) reviews, but obviously they are not part of the national M\&E framework.

\section{The role of non-state actors}

Various sources for M\&E demand and supply can lie outside government structures. Many of these outside actors not only increase demand but may also offer interesting information and analysis of the achievements and/or shortcomings of national policies. The independence - in principle - of non-state actors is also advantageous.

In line with the principles of parliamentary democracy, the Rwandan parliament is supposed to act as an interpellator of (or control on) the national government. On paper at least, this should constitute a powerful demand agent for M\&E. Yet the Rwandan parliament is still in 'a process of learning and consolidating its newly found autonomy' (Evans et al. 2006: 65). It currently only deals with summaries of M\&E reports, and 
little independent demand or supply can be expected from it in the short term. ${ }^{13}$

Under the 2003 Constitution (Art. 183-4), the Office of the Auditor General (OAG) is the supreme audit institution of Rwanda. In some countries, it also plays an important role in evaluation. Apart from controlling and checking accounting and spending (i.e. financial audits), shedding light on the efficiency, economy and effectiveness of policies, programmes, etc. (i.e. performance audits) also forms part of its mission. Although the Rwandan OAG sometimes voices criticisms, it mainly targets the technical input of the public sector (whether tender procedures, procedures of recruitment, etc. were followed or not). More critical issues, such as the intermingling of the public and private sectors in Rwanda, are typically not scrutinised. Although performance auditing lies within the OAG's mandate, currently there are no personnel to take up the task (Amis et al. 2005: 7), nor are there institutional forces/incentives to encourage it.

Potentially important sources for M\&E supply (and demand) are national research institutes and universities. Of course, the capacities of universities and institutes have to be seen in perspective; the genocide explicitly targeted intellectuals and, accordingly, the National University of Rwanda suffered severely in i994. Nevertheless, Rwanda currently possesses some highly trained and competent researchers and academics. We have already noted the Poverty Reduction Policy Relevance Test and the Citizen Report Cards, interesting M\&E initiatives conducted by the National University of Rwanda in collaboration with OSSREA. Whereas such initiatives are laudable, there remain many weaknesses (and it is not always clear whether they are due to deficits in capacity or autonomy). Mandatory prior authorisation by the government of research initiatives could potentially discourage researchers from working in sensitive areas such as the current land reforms. It is not unlikely that this leads, a priori, to self-censorship by researchers. In fact, self-censorship is not unusual in Rwanda. Mutebi et al. (200r: I5) refer to an editor-in-chief who indicated that newspapers routinely practice self-censorship as " "a survival mechanism", given the fact that the public and the government are far from tolerant towards "excessive criticism" of the government during what is regarded a period of national healing'. According to some of our interviewees (staff members of international NGOs, 2006 int.), other practices such as senior staff co-optation (e.g. the appointment of the rector of the National University of Rwanda and the overwhelming of critical researchers and professors with administrative, teaching activities and international functions, etc.) could be similarly judged. 
The combined effect of this results in too little sound, independent and critical M\&E supply from Rwandan universities, institutes or research centres.

National and international NGOs are another important set of actors in Rwandan civil society. While some representatives indicated that policy making has become more participatory and inclusive since 2000 (Evans et al. 2006; Purcell et al. 2006), NGOs have not been accorded a consistent and formal role in the monitoring and evaluation of the PRSP. ${ }^{14}$ There is also a tendency for the GoR to talk only with umbrella organisations, mainly for reasons of diplomacy and manageability. Given the increasing number of 'briefcase' NGOs in Rwanda, the issue of NGOs and CSOs 'representativeness' is certainly valid (Evans et al. 2006: 6I). However, it may equally hold for umbrella organisations that tend to be located in Kigali, and increasingly become alienated from the poor in rural areas. While there is little critical analysis and demand coming from national and international NGOs, the formal room for such criticism may not be entirely non-existent. One respondent (an international NGO staff member, 2006 int.) interestingly compared the position of NGOs in Rwanda to the well-known image of chickens transported to the African markets, legs tied together. Upon arrival its owner can easily untie the legs; the animal will remain in the same, cramped, position, unconscious of its regained freedom. Remarkable, and indicative of the room for manoeuvre that does exist, is the fact that national and international NGOs have joined forces in collectively commenting on the 2004 Annual Progress Report. ${ }^{15}$ The comments were extremely relevant and highlighted the absence in the report of impact analyses of poverty reduction with particular reference to prima facie pro-environment measures, ${ }^{\mathbf{1 6}}$ the lack of smart indicators, the problem of the choice of international language in Rwanda (English $v$. French) ${ }^{17}$ and the flawed discussion of governance issues. These comments can be read as a questioning of the pro-poor character of the PRSP policy. The civil society report did not, it seems, make it to the central level of government, nor were its concerns taken up by the international community.

In short, as Purcell et al. (2006: 52) point out, 'overall, the policy process remains rather "top-down", with major policy shifts prepared by small high-powered executive task forces, limited consultation (including of International Partners) especially on potentially sensitive issues, and Cabinet approval marking an almost immediate start of implementation'. Furthermore, and particularly relevant in the context of this research on $\mathrm{M} \& \mathrm{E}$, is the fact that 'the top-down nature of the policy process puts limits on the experience feeding into learning and adaptation; this is a 
government which is convinced that it knows what is best for its people' (ibid.: 55). The interpretation given in Rwanda to 'participation' and even 'consultation' in terms of 'persuasion' and 'consciousness-raising' has been discussed elsewhere (Pottier 2006).

\section{Donor behaviour in $M \mathcal{E}^{2} E$}

In the first place, donors' demands for $\mathrm{M} \& \mathrm{E}$ are driven by their own accountability needs to their constituencies. Only second come donor concerns for iterative learning in the partner country. Here again, the split between budgetary and non-budgetary donors to Rwanda is important. In general, the latter are more critical about the political situation in the country (poor human rights record, limited freedom of speech, silencing of opposition, the abuse of the notion of divisionism, etc.) and the region (e.g. Rwanda's involvement in the Congo war). They tend to follow 'older' aid modalities, in particular donor-managed project interventions and technical assistance. Depending upon the type of support, donors create different types of $\mathbf{M} \& \mathrm{E}$ demand. Important non-budgetary donors are Belgium, ${ }^{18}$ Germany, the Netherlands, USAID, Japan and Canada. Among them there are some minor variations in the use of the Rwandan national M\&E system. Some donors use the national system to a limited extent to monitor their projects (at times it is only seen as a reporting obligation), whereas others (e.g. USAID) do not use this at all (Amis et al. 2005). In general, non-budgetary donors are reluctant to use national M\&E due to its poor quality, reliability and independence. Similarly, they do not provide significant incentives and demands for the elaboration of a strong national M\&E system. While changes are discernable (such as in the education sector), donors are predominantly driven by learning and accountability questions that are directly related to their own interventions. They still do not provide useful information from their own project and programme $\mathrm{M} \& \mathrm{E}$ exercises into national $\mathrm{M} \& \mathrm{E}$ systems. Their desire to satisfy their own M\&E demands makes them oblivious to the need to also build a nationally integrated M\&E system. This manner of conducting $\mathrm{M} \& \mathrm{E}$ is obviously not in line with the Paris Declaration on Harmonisation and Alignment. Budgetary support donors, from their side, embrace the logic of strengthening the national system and this makes them potential 'cheerleaders ${ }^{\text {'19 }}$ for a strong national M\&E system. Some donors provide technical assistance to MINECOFIN (Belgium, WB and DfID). DfID, one of the most important budgetary donors, has invested a lot in building an education sector M\&E system. Yet what is missing is similar support to the central M\&E system (Kanyarukiga et al. 
2006: 4I). Unlike elsewhere, there is, for example, no working group on M\&E in Rwanda. The Development Partnership Framework has not focused, so far, on a harmonised approach to M\&E, even though this would be a huge step forward in harmonisation and alignment, and a reduction of the $\mathrm{M} \& \mathrm{E}$ burden.

$\mathrm{M} \& \mathrm{E}$ in the education sector is an interesting experiment in terms of harmonisation and alignment. The education sector is the most advanced in terms of M\&E in Rwanda (Evans et al. 2006; Hayman 2007; MINECOFIN 2006; OECD/DAC 2007b; Purcell et al. 2006), and several Joint Sector Reviews (JSRs) have taken place (MINEDUC 2006). Under the strong leadership of DfID, non-budgetary donors have started using these JSRs in the education sector for their own M\&E purposes, but that process has only just begun. For both groups of donors, there are clearly incentives towards better integration. Characteristic for budgetary donors is that they often no longer engage at the local level, which, of course, cuts them off from local knowledge and realities. In their evaluation of the 2000-5 DfID Rwanda Country programme, Kanyarukiga et al. (2006: 4I) explicitly indicate 'that DfID Rwanda is very strongly oriented at central agencies; it is distant from other important players in line ministries and local government and insufficiently informed about implementation realities on the ground'. Furthermore, the Management Information System (MIS) in the Rwandan education sector is weak and gives at best a picture of actual users. It does not provide information on those that currently remain out, which is essential in a context of potentially exclusionary outcomes. Through cooperation, budgetary donors get reality-checks from the field, and information from non-budgetary donors is at least used beyond the project and programme level. Furthermore, participation in JSRs provides non-budget support donors with increased insight into the sector in which they are funding particular projects, programmes or target populations. If they gain trust in the process, it could eventually convince them to align at the sector system, abandoning at least part of the repetitious and burdensome project M\&E exercises and focusing increasingly on those $\mathrm{M} \& \mathrm{E}$ activities that are worthwhile beyond the specific project. In spite of the advantages of such integration, the substantial divide between budgetary and non-budgetary donors remains a continuous threat to current $\mathrm{M} \& \mathrm{E}$ practices, and the elaboration of a sound sectoral and national M\&E system. Referring to interviews with donor agencies, Hayman (2007: 376) highlighted that 'smaller donors to the [education] sector, such as France, Belgium and Germany often feel excluded from discussions'. In our own interviews with staff of various non-budgetary donors (2006 int.), several indicated that evidence 
they had presented during JSRs or cluster meetings was often rejected as 'anecdotal' and 'invalid'.

In terms of support for the creation of a national (and independent) $\mathrm{M} \& \mathrm{E}$ demand side, which might give impetus to 'downward accountability' (one of the crucial ingredients of the new aid paradigm), donors to Rwanda are ambiguous. On one hand, they are fully aware of its importance, yet on the other no action is taken. While donors funding NGOs in Rwanda (national and international) speak of 'furthering an enabling environment' for civil society, on the ground there is little evidence of this. They even do little cross-reading between the information they get from civil society and their own (donor) involvement. This contrasts sharply with Uganda, where information on governance issues provided by the Ugandan Debt Network fed into the decision of DfID to reduce its budget support to the Ugandan government (Cordaid 2005: 3I).

B ELOW THE S URFACE: THE DENIAL OF POLITICS IN M\&E UNDER

THE NEW AID MODALITIES

While differing $\mathrm{M} \& \mathrm{E}$ observations (and conclusions) from a narrow methodological and technical perspective on one hand and from a broader institutional and systemic view on the other may appear surprising, these can, to a large extent, be attributed to one of the most serious flaws in the new aid paradigm: the denial of 'politics'. 'The conception of the PRS approach as being based upon an unwarranted faith in a technocratic, depoliticised mode of governance' (Craig \& Porter 2003) is increasingly acknowledged in academic aid literature (Armon 2007; Booth 2005; Driscoll \& Evans 2005). This suggestion particularly holds when it comes to 'monitoring and evaluation', where donors and recipients both adopt a skewed technocratic approach, vigorously neglecting the fact that $\mathrm{M} \& \mathrm{E}$ takes place within a socio-political setting that can heavily impinge upon it.

The fact that politics are part and parcel of M\&E has long been acknowledged in the context of project and programme evaluation (Palumbo 1987; Weiss 1970, 1987). First, evaluations are supposed to feed into decision making and reports necessarily enter the political arena. ${ }^{20}$ Second, evaluations implicitly make political statements about the legitimacy, utility and appropriateness of projects and/or programmes. Third, since projects and/or programmes are creations of political decisions that remain subject to pressure(s) during implementation, the issue of politics is inevitable during evaluation (Weiss 1970). While the relationship between politics and evaluation is potentially damaging, not 
all political aspects of evaluation need to be understood negatively. For example, for utilisation-focused evaluations, usage is the driving force. Consequently the evaluator is encouraged to tie the evaluation into the specific political context, and the needs of the users (Chelimsky I987a, I987b; Patton 1987; Weiss 1999).

With the broadening of programme scope, as indicated by Weiss (1970), the politics of evaluation will become more pervasive and reach the national level. This is also true when M\&E concerns interventions at the sectoral and national levels, and stakeholders and interests are multiplied. In this respect, Killick (2004: 5) refers to the often made suggestion that 'the potential seriousness of the tensions among evidence on the one hand and preferences of politicians and incentive structures to which they are responding has been magnified by the trend within the new aid agenda for aid modalities to become more "macro"-based'.

Moreover, the new aid paradigm rightly puts the national government in the driver's seat, also when it comes to M\&E. One can assume therefore that national politics and the political context in which stakeholders, both national and international, operate will have an influence on various dimensions of $\mathrm{M} \& \mathrm{E}$. While some recent contributions have pointed to the importance of taking a broader perspective on M\&E (Bedi et al. 2006; Kusek \& Rist 2004), there has so far been no research that explicitly explores the linkages between 'politics' and M\&E in the context of the new aid modalities. Though it is beyond the scope of this article to fill the gap, we point to some elements that might be worth further exploration. As in previous sections, we illustrate with Rwanda case study material, but the general discussion is applicable to all countries where the new aid modalities are applied.

One concept from political theory that might prove useful in structuring future research on the linkage between 'politics' and M\&E is the 'Political Opportunity Structure' (POS), which refers to the political context in which stakeholders operate. Initially the POS was considered a static framework of institutional variables, including stable aspects of government structure such as the administrative structures and/or institutional entities that could influence the position and power of stakeholders in society (Tilly 1978). Later, POS theory evolved towards a more dynamic model, giving recognition to the influence of more volatile aspects such as national policies, turnover of power and shifts in electoral outcomes (McAdam I999). The POS of a country is considered to be in continuous evolution, with the evolution of both stable and volatile aspects depending very much upon the interests and power of the political elite. Changing or influencing the POS is not, however, the sole sanctuary of this elite. By 
defending and/or furthering their own interests, various stakeholders, including donors and CSOs, may influence the POS (Meyer \& Staggenborg 1996). Of course, the 'action radius' of non-state actors will be circumscribed by government organisations and structures.

In terms of $\mathrm{M} \& \mathrm{E}$, it is obvious that different stakeholders may have their own interests, and the extent to which they are able to make their interests heard largely depends upon the POS. At the very least, there may be serious tensions between the political elites and ' $M \& E$ '. $M \& E$ is about 'learning' and 'accountability'. While, ideally, a government that is committed to inclusive development and poverty reduction will be eager to learn in order to improve its policies and outcomes, it would be naive to expect that political leaders and bureaucrats are always eager to learn from evidence. When less is known about what works and what does not, political leaders increase their room for manoeuvre (CGD 2006). Investment in evaluative exercises and 'knowledge' can even become counterproductive when, in cases like Rwanda, substantial amounts of general budget support can be generated without strong 'poverty-reducing credentials'. As Pritchett (2002: 268) puts it, 'if a program can already generate sufficient support to be adequately funded then knowledge is a danger'. Tensions between political elites and M\&E are particularly obvious when it comes to the 'accountability' function of $\mathrm{M} \& \mathrm{E}$. When policies are not implemented or targets not met, this may have implications for the politicians who were engaged to deliver them. As Booth (2005: 5) points out, 'The easy notion that donors only have to back off from demanding accountability for aid funds in order for domestic accountability to flower in its place is unrealistic and unhistorical.' Authoritarian regimes in particular are unlikely to stimulate the accountability aspect of $\mathrm{M} \& \mathrm{E}$ as this may directly jeopardise their power position: '.. the more dramatic the power asymmetries among actors - that is the more power the political élites possess relative to the power of citizens and their political opposition and other actors - the weaker the incentive is for such an élite to transform established $\mathrm{M} \& \mathrm{E}$ programmes into an instrument for more public sector accountability' (Gordillo \& Andersson 2004: 309).

The actions undertaken by governments to curtail critical analysis and insight may range from overt forms of repression and human rights abuse (e.g. no/limited freedom of speech, arbitrary detentions, etc.) to more covert forms. Institutional autonomy can be impeded; parliamentary power can be curtailed; autonomous organisations (such as the Auditor General's Office) can be captured or infiltrated by another government agency (co-optation), etc. At times, governmental interference can be very 
subtle. For example, overcentralised functioning can be used to delay and suffocate initiative, especially when coupled with the monitoring of independent actors through central registration, compulsory reporting, etc. ${ }^{21}$

While there are dramatic differences in donors' assessments of Rwanda's governance situation, mostly between budgetary and nonbudgetary donors, there is no disagreement that 'voice and accountability' is, indeed, a problem in Rwanda. Particularly illuminating in this regard is the latest update of the governance indicators of Kaufmann, Kraay and Mastruzzi (2007), which point to sharply differentiated rankings for Rwanda on 'control of corruption' ( $55^{\circ} 8$ percentile rank) and 'voice and accountability' (I4:4 percentile rank). Complementary to these indices are more qualitative contributions from other sources (Jordaan 2006; Reyntjens 2004), which illustrate that several government actions and incidents have led to a very restrained political climate and a serious curtailment of freedom of association and action. In Rwanda, 2003 was particularly pernicious for the freedom of speech. In that year the opposition party, Mouvement Démocratique Républicain (MDR), was banned and several CSOs (including the leading human rights organisation Liprodhor) were bashed in a parliamentary report. The run-up period to the constitutional referendum and the local elections further narrowed room for criticism and freedom of speech. Add to this the very restrictive law on CSOs that stipulates that 'associations have to apply yearly for a renewed recognition; that the Minister of Justice may suspend the activities of an organisation when she/he discretionally judges them a threat to the law, public order or good moral standards of the country' (Law $\mathrm{N}^{\circ} 20 / 2000$ ), then the self-censoring behaviour of CSOs (and international NGOs) starts to make sense. The least one can say is that Rwanda's 'straight-jacket-like' POS is not encouraging the development of an independent $\mathrm{M} \& \mathrm{E}$ demand side. Importantly, this hinders the operation of PRSP logic and its related paradigm that need independent $\mathrm{M} \& \mathrm{E}$ as sources for evidence-based learning and accountability.

In heavily aid-dependent countries, such as Rwanda, the POS is co-determined by the international (official) donor community, which also has its interests in partner countries and in the entire development enterprise. Not only does the GoR want to convince contributors and bystanders that it is doing well, donors have a similar stake in presenting 'success' to their constituencies (Marriage 2006). Budgetary support donors, in particular, cannot afford to be too openly critical of the national $\mathrm{M} \& \mathrm{E}$ systems that constitute a growing (input) source for their own reporting, without by the same token undermining the credibility of the latter. From that point of view, the not-too-critical approach is 
understandable. The lack of an open and critical approach can sometimes be justified on the condition that alternative more diplomatic (and hopefully effective) forms of pressure will pay off. We concur that politically sensitive matters should generally not be dealt with aggressively and in the open. Yet, when policy dialogue is chosen as the instrument, its effectiveness should be followed up. One could even argue that in states with nonenabling POS, where accountability is almost by definition problematic, more emphasis could be put on learning rather than accountability (Gordillo \& Andersson 2004). However, the temporary downscaling of accountability can only be justified if learning is truly taken seriously by all involved. Currently, however, donors focus overwhelmingly on 'procedures' and 'processes'. They also have a tendency to neglect matters of 'substance', even if various sources have raised substantial concerns over potentially exclusionary policies and outcomes on the ground. We acknowledge that this often involves sensitive and complex issues, but allowing a government to practically declare such issues 'off limits' for serious $M \& E$ is unlikely to contribute to evidence-based poverty reduction and inclusive poverty reduction policies. In fact, ignoring politically sensitive issues in evaluations and/or reviews can fundamentally affect the process to the point that it not only becomes oblivious of political flaws, but is also technically flawed and/or defective.

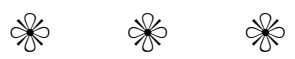

The new aid paradigm both reconfirms and redefines the importance of monitoring and evaluation. The 2005 Paris Declaration sets out an ambitious $\mathrm{M} \& \mathrm{E}$ reform agenda for both recipients and donors. Recipients are expected to elaborate an effective national M\&E system which is critical for the functioning of key components such as 'results-orientation', 'iterative and evidence-based policy making', and 'downward accountability'. At the same time, donors are asked to wind down their own parallel and independent systems, and move towards integrating into the national M\&E system. So far, donors and recipients have adopted a fairly fragmentary approach towards $\mathrm{M} \& \mathrm{E}$, emphasising input accountability, indicators and targets, data collection and monitoring of inputs and MDGs, largely neglecting evaluative analysis and, in particular, the broader more institutional and systemic issues. This generally observed phenomenon has similarly been evidenced with case study material from Rwanda. While Rwanda does score well on a narrow technocratic level, there are much more serious shortcomings at the broader systemic and institutional levels. 
We have argued that these striking differences boil down to one of the most serious flaws in the new aid paradigm: the denial of 'politics'. This is particularly valid and critical when it comes to M\&E. While the influence of 'politics' in M\&E has long been acknowledged in projects and programmes, it seems to be disregarded when moving to the national and sectoral levels (just when interests and stakeholders are multiplied). Whereas a narrow technocratic vision may seem 'politically neutral' and the only one that is feasible, it may at the same time undermine M\&E's functions of 'accountability' and 'feedback and learning', and even worsen 'political constraints'. It potentially further lowers public voice and accountability, strengthens government's M\&E monopoly, and hides and reinforces flaws in policies (which are particularly pernicious when they perpetuate existing exclusionary practices). It can eventually lead to the ineffective implementation of the key principles of the new aid approach and so undermine its very success.

\section{NOTES}

I. See OECD/DAC 2007a for an overview of the results of the first (2006) survey and OECD/DAC 2008 for the ongoing 2008 survey.

2. In view of many, including the GoR, the genocide was at least partly due to the failure of the international community to intervene (e.g. UN forces could have been given a broader mandate to react).

3. Of the five key dimensions of the Paris Declaration (ownership, alignment, harmonisation, managing for results, and mutual accountability), it is the only one labelled 'strong' on an ordinal measure low/moderate/strong.

4. Interestingly, in its assessment of the actual state of M\&E recipients' systems on the ground, the 2005 Comprehensive Development Framework evaluation contrasts considerable improvements in sub-components such as statistical data capacity with meagre ones in developing 'coordinated' monitoring systems (World Bank 2005).

5. The Statistical Capacity Building Index is a composite index including scores on three subdimensions: statistical practice (the ability to adhere to internationally recommended standards and methods); data collection (frequency of censuses/surveys and completeness of vital registration); and indicator availability (availability and frequency of key socioeconomic indicators) (IMF/WB 2005; World Bank 2008). The 2007 scores on the three sub-dimensions are 70,60 and 82 for Rwanda, and 59, 6o and 79 for the average low- and middle-income country (World Bank 2008).

6. Poverty Reduction Policies Relevance Tests can be particularly useful as (ex ante) appraisal tools for assessing the degree to which envisaged policies are likely to have contributed to poverty reduction.

7. This finding confirms cross-country empirical evidence and analyses for a broad range of developing countries provided in Ravallion (2007).

8. Stewart (2006: 2) defines horizontal inequalities as '(social, economic and political) inequalities among groups with shared identities - identities formed by religion, ethnic ties or racial affiliations, or other salient ways that bind groups of people together'. They are often an important element behind mobilisation for conflict.

9. The GoR justifies this as a means of fostering peace in a deeply traumatised population, but ethnic differences are paramount and do constitute the basis of social and political exclusion. The fact that the regime is largely perceived within the country as being Tutsi-dominated adds a critical element in understanding why the taboo on discussing ethnic differences is so controversial.

I0. The 2006 Joint Sector Review even acknowledged this lacuna and referred to the awaited results of the second household survey, which have been available since the beginning of 2007. It is too 
soon, however, to assess to what extent the education sector has actually seized on the new opportunities for cross-reading and analysis.

II. Several interviewees at ministerial level (returnees) (2006 int.) acknowledged that they were totally ignorant of the situation outside Kigali. Positively, transfer to the district level might give them an opportunity to get first-hand information on rural realities and the chance to understand the rural population's needs and incentives.

I2. Particularly relevant in the context of this research are the African Evaluation Guidelines, which are a modified version of the Program Evaluation Standards, which in turn are based upon widespread discussion and consultation within the African Evaluation Association (Nairobi M\&E Network 2002).

I3. Various parliamentary reports displayed a lack of independence and appeared to represent the RPF party cause. One of the most notable is the so-called 2004 Report on Divisionism (Commission Parlementaire 2004).

I4. See Renard \& Molenaers (2003) on the participation of civil society in the first PRSP.

I5. The comments produced and communicated to the GoR are based on meetings attended by thirteen international and national organisations: CCOAIB, ADTS, GESTRAR, Centre Iwacu, CAURWA, Profemme Twese Hamwe, Trocaire, CARE International, AVSI, Concern World Wide, Oxfam GB, NPA and Africare (Anon. 2005).

I6. Measures that have been partly justified on environmental grounds include the land reform policy (Pottier 2006: 520) and the abolition of brickyards (an activity overwhelmingly dominated by the Twa, a marginalised ethnic group that has little experience with alternative economic activities).

17. There is a significant language shift in Rwanda in favour of English (spoken by returnees) to the detriment of French as a second international language after Kinyarwanda (which is spoken throughout the territory, if not by some returnees). This language change hinders the largest part of the population from participating in society and even from staying informed. Prior to the I994 genocide, Rwandan NGO staff and intellectuals used French as their second language. Important anglophone donors reinforce this language bias which eventually works (unintentionally) to the detriment of the poor (Browne 2007; Kanyarukiga et al. 2006: I4, 4I-2).

I8. The situation is gradually changing as in the case of Belgium, which is moving increasingly towards sectoral budget support. Over the period 2006-7, it has disbursed about $€_{3.5}$ million in the Joint Education Sector Support Programme and from 2008 onwards it plans to support both the educational and health sector through sectoral budget support (for an amount of $€ 8$ million each). Belgium will also become the lead donor in the health sector.

I9. The notion of cheerleader has been adopted by the World Bank (2000).

20. Although the relationship may not always be that straightforward, see Weiss (1999).

21. Bratton (1989) distinguishes dissolution, co-optation, coordination and monitoring.

\section{R E F E R E N C E S}

Amis, P., P. Jackson \& G. Ahobamuteze. 2005. 'Baseline survey of donor alignment and harmonisation in Rwanda', University of Birmingham, International Development Department.

Anon. 2005. '2004 Rwanda PRS Annual Progress Report: joint civil society comments on the zero Draft of I7th June 2005', Kigali.

Armon, J. 2007. 'Aid, politics and development: a donor perspective', Development Policy Review 25, $5: 653-6$.

Bamberger, M. 1989. 'The monitoring and evaluation of public sector programs in Asia: why are development programs monitored but not evaluated?', Evaluation Review I3, 3: 223-42.

Bamberger, M. 199I. 'The politics of evaluation in development', Evaluation and Program Planning I4: 325-39.

Bamberger, M. 200o. 'The evaluation of international development programs: a view from the front', American Foumal of Evaluation 21, I: 95-102.

Bedi, T., A. Coudouel, M. Cox, M. Goldstein \& N. Thornton. 2006. Beyond the Numbers: understanding the institutions for monitoring poverty reduction strategies. Washington, DC: World Bank.

Booth, D. \& H. Lucas. 2002. 'Good practice in the development of PRSP indicators and monitoring systems', ODI working paper I72, London: ODI.

Booth, D. 2005. 'Missing links in the politics of development: learning from the PRSP experiment', ODI working paper 256, London: ODI.

Bratton, M. 1989. 'The politics of government - NGO relations in Africa', World Development 17: 569-87. 
Brown, G. \& F. Stewart. 2007. 'The implications of horizontal inequalities for aid', UNU-WIDER discussion paper 2007/5I, Helsinki: UNU-WIDER.

Browne, S. 2007. 'Aid to fragile states: do donors help or hinder?', UNU-WIDER discussion paper 2007/or, Helsinki: UNU-WIDER.

Centre for Global Development (GGD), Evaluation Gap Working Group. 2006. When Will We Ever Learn? Improving lives through impact evaluation. Washington DC: CGD.

Chelimsky, E. 1987a. 'What have we learned about the politics of program evaluation?', Evaluation Practice 8, I: 5-21.

Chelimsky, E. I987b. 'Linking program evaluation to user needs', in D. Palumbo, ed. The Politics of Program Evaluation. London: Sage, $72-99$.

Commission Parlementaire. 2004. Là où l'idéologie génocidaire se fait observer au Rwanda. Kigali: Commission Parlementaire.

Cordaid. 2005. Beyond Data: a panorama of CSO experiences with PRSP and HIPC monitoring. Den Haag: Cordaid.

Craig, D. \& D. Porter. 2003. 'Poverty reduction strategy papers: a new convergence', World Development 31, I: 53-69.

Development Gateway Foundation Inc. 2008. <www.aidharmonisation.org >

Development Partners Coordination Group (DPCG). 2007. Rwanda Development Partners Website. $<$ http://www.devpartners.gov.rw >

Driscoll, R. \& A. Evans. 2005. 'Second generation poverty reduction strategies: new opportunities and emerging issues', Development Policy Review 23, I: 5-25.

Elkins, C. 2006. 'Monitoring and evaluation (M\&E) for development in peace-precarious situations', paper prepared for the 47 th Annual ISA Convention San Diego, CA.

Evans, A., L. Piron, Z. Curran \& R. Driscoll. 2006. Independent Evaluation of Rwanda's Poverty Reduction Strategy 2002-2005 (PRSPI). London/Brighton: ODI/IDS.

Gordillo, G. \& K. Andersson. 2004. 'From policy lessons to policy actions: motivation to take evaluation seriously', Public Administration and Development 24, 4: 305-20.

GTZ/BMZ (Deutsche Geschellschaft fưr Technische Zusammenarbeit/German Federal Ministry for Economic Cooperation and Development). 2004. National Monitoring of Strategies for Sustainable Poverty Reduction/PRSPs, vol. I. Main Report. Eshborn: GTZ.

Hayman, R. 2007. 'Are the MDGs enough? Donor perspectives and recipient visions of education and poverty reduction in Rwanda', International foumal of Educational Development 27: 37I-82.

Holvoet, N. \& R. Renard. 2007. 'Monitoring and evaluation under the PRSP: solid rock or quicksand?', Evaluation and Program Planning 30, I: 66-8I.

IMF \& World Bank. 2005. 2005 Review of the Poverty Reduction Strategy Approach: balancing accountabilities and scaling up results. Washington DC: IMF \& World Bank.

Jordaan, E. 2006. 'Inadequately self-critical: Rwanda's self-assessment for the African Peer Review Mechanism', African Affairs 105, 420: 333-51.

Kaufmann, D., A. Kraay \& M. Mastruzzi. 2007. Governance Matters vi: governance indictors for 1996-2006. Washington, DC: The World Bank. < http://info.worldbank.org/governance/wgizoo7>

Kanyarukiga, S., E. Van Der Meer, M. Paalman, D. Poate \& T. Schrader. 2006. 'Evaluation of DfID Country Programmes: Country Study Rwanda 2000-2005’, DfID Evaluation report EV66o. London: DfID.

Killick, T. 2004. 'Politics, evidence and the new aid agenda', Development Policy Review 22, I: 5-29.

Kusek, J. \& R. Rist. 2004. Ten Steps to Results-based Monitoring and Evaluation System. Washington, DC: World Bank.

'Loi $\mathrm{N}^{\circ}$ 20/2000 du 26/o7/2000 relative aux associations sans but lucrative', fournal Officiel $\mathcal{N}^{\circ} 7 \mathrm{du}$ oI $/$ $04 / 2001,39-47$.

Lucas, H., D. Evans \& K. Pasteur. 2004. 'Research on the current state of PRS monitoring systems', IDS discussion paper 382 , Brighton: IDS.

McAdam, D. 1999. Political Process and the Development of Black Insurgency 1930-1970, 2nd edn. Chicago, IL: University of Chicago Press.

Marriage, Z. 2006. 'Defining morality: DFID and the Great Lakes', Third World Quarterly 27, 3: $477-90$.

Meyer, D. \& S. Staggenborg. 1996. 'Movements, counter-movements and structure of political opportunity', American Fournal of Sociology гог: I628-60.

Ministry of Education, Government of Rwanda (MINEDUC). 20o6. Revue Conjointe du Secteur de l'Éducation (JRES). Kigali: MINEDUC. 
Ministry of Finance \& Economic Planning, Government of Rwanda (MINECOFIN). 2005. Cabinet Paper on the National Poverty Reduction Strategy Monitoring and Evaluation Framework. Kigali: MINECOFIN.

MINECOFIN. 2006. Aid Effectiveness Report Rwanda: annual report. Kigali: MINECOFIN.

MINECOFIN, National Poverty Reduction Programme, UNR Butare and Ossrea Rwanda Chapter. 2002. Poverty Reduction Policies Relevance Test, vols I-v. Kigali: MINEGOFIN, UNR Butare and Ossrea Rwanda Chapter.

Mutebi, F. G., S. Stone \& N. Thin. 200I. Institutionalising the PRSP Approach in Rwanda (Chapter 8 of the PRSP Institutionalisation Study). Oxford: Oxford Policy Management.

Nairobi M\&E Network. 2002. 'The African Evaluation Guidelines, 2002: a checklist to assist in planning evaluations, negotiating contracts, reviewing progress and ensuring adequate completion of an evaluation', Evaluation and Program Planning 25, 4: 48I-92.

National Institute of Statistics Rwanda (NISR). 2006. Preliminary Poverty Update Report: integrated living conditions survey 2005/06 (first draft for consultation). Kigali: NISR.

OECD/DAC. 2002. Key Terms in Evaluation and Results Based Management. Paris: OECD/DAC.

OECD/DAC. 2005. Paris Declaration on Aid Effectiveness. Paris: OECD/DAC.

OECD/DAC. 2007a. 2006 Survey on Monitoring the Paris Declaration: overview of the results. Paris: OECD/ DAC. < http://www.oecd.org/dac/effectiveness/monitoring >

OECD/DAC. 2007b. 2006 Survey on Monitoring the Paris Declaration: Rwanda chapter. Paris: OECD/DAC.

OECD/DAC. 2008. 2008 Survey on Monitoring the Paris Declaration. Paris: OECD/DAC. < http://www. oecd.org/dac/hlfsurvey>

OSSREA Rwanda Chapter. 2006. Rwanda Citizens Report and Community Score Cards. Kigali: OSSREA Rwanda Chapter.

Palumbo, D. ed. I987. The Politics of Program Evaluation. London: Sage.

Palumbo, D. I987. 'Politics and Evaluation', in Palumbo, The Politics of Program Evaluation, I2-46.

Patton, M. Q. I987. 'Evaluation's political inherency: practical implications for design and use', in Palumbo, The Politics of Program Evaluation, IOO-45.

Picciotto, R. 2003. 'International trends and development evaluation: the need for ideas', American Foumal of Evaluation 24, 2: 227-34.

Pottier, J. 2006. 'Land reform for peace? Rwanda's 2005 land law in context', fournal of Agrarian Change $6,4: 509-37$.

Prennushi, G., G. Rubio G. \& K. Subbarao. 200I. 'Chapter 3: Monitoring and Evaluation + Annexes', in World Bank, PRSP Sourcebook. Washington DC: World Bank, I07-30; $433^{-62 .}$

Pritchett, L. 2002. 'It pays to be ignorant: a simple political economy of rigorous program evaluation', Policy Reform 5, 4: 25I-69.

Purcell, R., C. Dom \& G. Ahobamuteze. 2006. Foint Evaluation of General Budget Support 1994-2004. Rwanda Country Report. Birmingham: International Development Department (IDD) and Associates.

Ravallion, M. 2006. 'Looking beyond averages in the trade and poverty debate', World Development 34, 8: $1374-92$.

Ravallion, M. 2007. 'Inequality is bad for the poor', in S. Jenkins \& J. Micklewright, eds. Inequality and Poverty Re-Examined. Oxford University Press.

Renard, R. \& N. Molenaers. 2003. 'Civil society participation in Rwanda's poverty reduction strategy', IDPM discussion paper 2003-5. Antwerp: IOB.

Reyntjens, F. 2004. 'Rwanda, ten years on: from genocide to dictatorship', African Affairs I03: I77-2Io.

Rombouts, H. 2004. Victim Organisations and the Politics of Reparation: a case study on Rwanda. Antwerp: Intersentia.

Strategic Partnership with Africa (SPA) - Budget Support Working Group (BSWG). 2005. '2004 Survey of the Alignment of Budget Support and Balance of Payments Support with National PRS Processes', report by the BSWG co-chairs (final draft 7 February 2005).

Stewart, F. 2006. 'Policies towards horizontal inequalities in post-conflict reconstruction', UNUWider research paper 2006/I49, Helsinki: UNU-Wider.

Tilly, C. I978. From Mobilization to Revolution. Reading, MA: Addison-Wesley.

Uvin, P. 200I. 'Difficult choices in the new post-conflict agenda: the international community in Rwanda after the genocide', Third World Quarterly 22, 2: 177-89.

Weiss, C. I97o. 'The politicization of evaluation research', foumal of Social Issues 26, 4: 57-68.

Weiss, C. I987. 'Where politics and evaluation research meet', in Palumbo, The Politics of Program Evaluation, 47-69.

Weiss, C. I999. 'The interface between evaluation and public policy', Evaluation 5, 4: 468-86. 
World Bank. 200o. Monitoring and Evaluation Capacities in Ghana: a diagnosis and proposed action plan. Washington, DC: World Bank.

World Bank. 2002. 2002 Annual Report on Evaluation Capacity Development. Washington, DC: World Bank, Operations Evaluation Department.

World Bank. 2003. Toward Country-Led Development: a multi-partner evaluation of the comprehensive development framework. Synthesis Report. Washington, DC: World Bank.

World Bank. 2005. Enabling Capacity to Achieve Results: 2005 comprehensive development framework progress report. Washington, DC: World Bank, Operations Evaluation Department.

World Bank. 2006. World Development Indicators Database 2006. Washington, DG: World Bank.

World Bank. 2008. Country Statistical Information Database. <http://go.worldbank.org/ MUOSWQBHDo>

\section{Interviews}

Staff members of national and international NGOs, Kigali, II.5.2006, I5.5.2006, I7.5.2006, I8.5.2006, I9.5.2006.

Staff from various non-budgetary donors, Kigali, I2.5.2006, I5.5.2006, 17.5.2006.

Staff members of ministries, Kigali, I2.5.2006, I5.5.2006, 18.5.2006, I9.5.2006. 